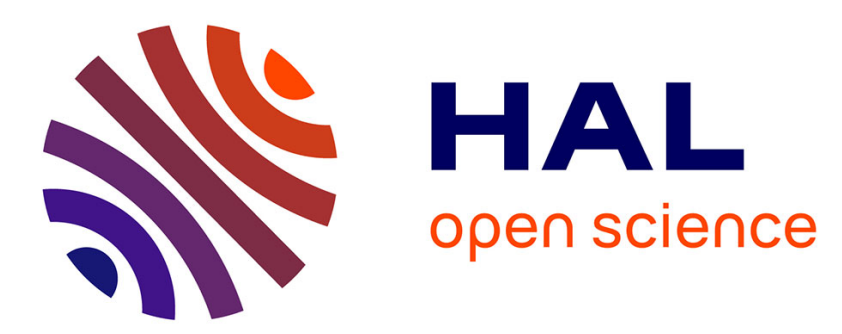

\title{
Experimental study of the influence of low frequency flow modulation on the whistling behavior of a corrugated pipe
}

Ulf R. Kristiansen, Pierre-Olivier Mattei, Cédric Pinhède, Muriel Amielh

\section{- To cite this version:}

Ulf R. Kristiansen, Pierre-Olivier Mattei, Cédric Pinhède, Muriel Amielh. Experimental study of the influence of low frequency flow modulation on the whistling behavior of a corrugated pipe. Journal of the Acoustical Society of America, 2011, 130 (4), pp.1851-1855. 10.1121/1.3628665] . hal-00628704

\section{HAL Id: hal-00628704 https://hal.science/hal-00628704}

Submitted on 19 Nov 2019

HAL is a multi-disciplinary open access archive for the deposit and dissemination of scientific research documents, whether they are published or not. The documents may come from teaching and research institutions in France or abroad, or from public or private research centers.
L'archive ouverte pluridisciplinaire HAL, est destinée au dépôt et à la diffusion de documents scientifiques de niveau recherche, publiés ou non, émanant des établissements d'enseignement et de recherche français ou étrangers, des laboratoires publics ou privés. 


\title{
Experimental study of the influence of low frequency flow modulation on the whistling behavior of a corrugated pipe
}

\author{
Ulf R. Kristiansen ${ }^{\text {a) }}$ \\ Acoustics Research Centre, Department of Electronics and Telecommunications, Norwegian University \\ of Science and Technology, 7491 Trondheim, Norway \\ Pierre-Olivier Mattei and Cedric Pinhede \\ Laboratoire de Méchanique et d'Acoustique, CNRS, 31 Chemin Joseph Aiguier, 13009 Marseille, France \\ Muriel Amielh \\ Institut de Recherche sur les Phénomènes Hors Équilibre, 49 rue F. Joliot Curie, 13013 Marseille, France
}

(Received 6 December 2010; revised 4 August 2011; accepted 4 August 2011)

\begin{abstract}
It is well known that airflow in a corrugated pipe can excite whistling at the frequencies of the pipe's longitudinal acoustic modes. This short contribution reports on the results of experiments where a low frequency, oscillating flow with velocity magnitudes of the same order as the airflow has been added. Depending on the oscillation strength, it has been found that this flow may silence the pipe or move the whistling to higher harmonics. It is also shown that the low frequency oscillation itself may excite higher frequency whistling sounds in the pipe.
\end{abstract}

(C) 2011 Acoustical Society of America. [DOI: 10.1121/1.3628665]

PACS number(s): 43.28.Ra, 43.28.Py, 43.25.Gf [AH]

Pages: 1851-1855

\section{INTRODUCTION}

Sound production in corrugated pipes has been a topic for scientific investigation for almost a century. In the form of short, flexible pipes these have been used in physics laboratory demonstrations and to provide amusement as musical toys, but have also been a topic for serious scientific research. The underlying physics involves a close interaction between the flow and the acoustics. Kristiansen and Wiik ${ }^{1}$ have presented a review of the literature on the topic up to 2006. The studies up to that time were largely experimental. Recent contributions include Debut et al., ${ }^{2}$ who modeled the acoustic sources by a distribution of van der Pol oscillators along the pipe, Goyder, ${ }^{3}$ who studied the acoustic source/ sink distribution along a corrugated pipe using the cavity impedances, and Tonon et al. ${ }^{4}$ who found similarities between pipes having multiple side branches and straight corrugated pipes. More recently Nakiboglu et al. ${ }^{5}$ provided information on the effects of cavity geometries and pipe lengths on the whistling behavior including a method to estimate the radiated acoustic source power.

The general topic has received renewed interest, in particular, with the so called "singing riser" problem which has become apparent in the natural gas industry. Long flexible pipes necessary for conveying gas are corrugated on the inside and are known to exhibit strong sound levels of pure tones at some offshore installations. A study directly treating the singing riser problem was recently published by Belfroid et al. ${ }^{6}$

Using a simple experimental arrangement, the authors of the present communication found that the addition of a low frequency oscillation significantly influences the flow-excited whistling in a short corrugated pipe. Moreover, it was found that the whistling could be silenced or moved to higher fre-

\footnotetext{
a) Author to whom correspondence should be addressed. Electronic mail: ulf.kristiansen@iet.ntnu.no
}

quencies, and also that the low frequency oscillation itself may excite whistling at the frequencies corresponding to the pipe's longitudinal modes. In this communication the physics of the underlying phenomena has been our primary interest. As the low frequency oscillation velocities are of a similar order of the flow velocities that normally excite the pipe whistle, it should be stressed that we do not include the addition of strong low frequency sound as a mitigation technique for the singing riser problem. Indeed, strong low frequency sounds could be as detrimental to the risers as the original flow generated tones.

A hard walled box was constructed with two openings, one connected to a short small diameter corrugated pipe, and the other to a vacuum cleaner able to draw air through the system. A loudspeaker, backed by a closed volume, was attached to one side of the box, for details see Sec. II. The arrangement effectively creates a type of Helmholtz resonator having two openings and an internal source of excitation. For low excitation frequencies, where the wavelengths are much longer than the geometrical dimensions, the air in the pipe was expected to oscillate as a single fluid body and the pressure to decrease from the box toward the open end. The acoustic output of the loudspeaker depends on the loudspeaker characteristics and the details of the confining geometry. The acoustics of the resonator/source assembly was not studied in detail. A theoretical estimate of the Helmholtz resonance ${ }^{7}$ for the box volume and corrugated pipe alone is around $7 \mathrm{~Hz}$. The acoustic influence of the pipe/hose assembly connecting the box to the vacuum cleaner is not known. It was found that at $10 \mathrm{~Hz}$, the loudspeaker provided an adequate signal to observe the phenomenon.

Some preliminary acoustic pressure measurements related to the present research were presented by the authors at a recent symposium. ${ }^{8}$

\section{EXPERIMENTAL SETUP}

A sketch of the experimental setup is shown in Fig. 1. The inner box volume measures $300 \times 300 \times 548 \mathrm{~mm}$. The 


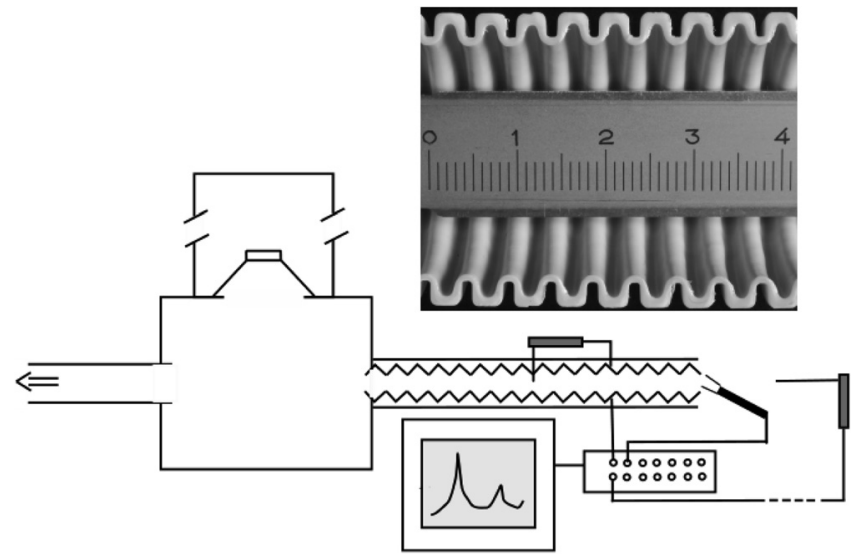

FIG. 1. A sketch of the experimental set up.

corrugated pipe has an inner diameter of $25.4 \mathrm{~mm}$, and is $627 \mathrm{~mm}$ long. One end is mounted flush with the box's inner surface. The cavity pitch is $5 \mathrm{~mm}$ and the depth is $2.4 \mathrm{~mm}$. The pipe geometry is shown in Fig. 1. In order to keep it straight the pipe was placed inside a close fitting rigid tube. A $42.5 \mathrm{~mm}$ inner diameter pipe connected the box to a vacuum cleaner via the vacuum cleaner hose. A $240 \mathrm{~mm}$ diameter loudspeaker is positioned at one of the box walls. The loudspeaker was fed $10 \mathrm{~Hz}$ signals between 0 and $12 \mathrm{~V}$. To minimize static pressure differences on both sides of the loudspeaker in a flow situation, it was backed by $0.07 \mathrm{~m}^{3}$ volume connected with the box through small holes. The steady flow velocity and the fluctuating acoustic signals were measured on the pipe axis and flush with the pipe's entry section by a hot-wire anemometer. At this section, the particle velocities of all the longitudinal pipe modes have high values. The steady flow velocity measured at this position is designated $U_{\mathrm{E}}$ (E for "entry"). The entry surface presents a slightly uneven sharp edge to the flow. This was cut between two cavity sections. An initial investigation of the steady axis velocity, a short distance into the pipe, showed that this velocity reached a local maximum of 1.45 $U_{E}$ at a distance of half the inner pipe diameter. This is assumed to be in the region of the vena contracta. The axis velocity of the developed flow further into the pipe was not measured, and no attempt was made to calculate the average flow velocity. Strouhal numbers based on $U_{E}$ and an appropriate length dimension were calculated for the flow excited resonances, see Sec. III. The appropriate length to use for the Strouhal number is presented in Nakigoblu et al. ${ }^{5}$ as the sum of the cavity width and the curvature radius of the flowside upstream cavity corner $\left(L_{c}=W+r_{\text {up }}\right)$. For the present geometry, these distances were measured as 1.7 and $1.5 \mathrm{~mm}$, respectively, where the cavity width was measured at half the cavity depth. The hot-wire probe is of type 55P11 and was operated by a DANTEC streamline CTA system. The sampling frequency was $10 \mathrm{kHz}$ and each recording consisted of 131072 samples. The whistling amplitudes were extracted from the associated frequency spectra. For single peaks, the amplitude was determined by integrating the energy in a narrow band around the peak. For the amplitudes of the $10 \mathrm{~Hz}$ loudspeaker generated signal, a $5 \mathrm{~Hz}$ bandwidth was used, while a $10 \mathrm{~Hz}$ bandwidth was used for the higher frequency whistling amplitudes. With the addition of a 10 $\mathrm{Hz}$ oscillation, the energy is distributed at a cluster of peaks where the width of the clusters depend on the $10 \mathrm{~Hz}$ source excitation level. The amplitude representing a cluster was determined by integration in a band wide enough to represent the cluster energy. Similar clusters of peaks have been discussed by Delprat in connection with modulated cavity flow. ${ }^{9}$ Sound pressures could also be measured at different positions using $1 \mathrm{~mm}$ diameter probe microphones (type G.R.A.S. 40SC), and analyzed by the DBFA suite 4.9 (01dB METRAVIB). A $12.8 \mathrm{kHz}$ sampling frequency was adopted in the sound pressure measurements.

\section{RESULTS}

\section{A. Flow generated whistling}

Figure 2 shows normalized particle velocities obtained by letting the vacuum cleaner draw air through the system at six Mach number $\left(U_{E} / c_{0}\right)$ ranges. The speed of sound $c_{0}$ is taken as $343 \mathrm{~m} / \mathrm{s}$ at $20{ }^{\circ} \mathrm{C}$. In Fig. 2 the amplitude values represent the dominant whistling modes at the corresponding Mach number and those belonging to the same mode are connected. Note that the markers defined in the legend of Fig. 2 are used throughout the paper. Whistling at the frequency of the fundamental longitudinal mode could not be excited (see Tonon et $a l .{ }^{10}$ ), interestingly nor was whistling at the frequency of the seventh mode appreciably excited either.

The whistling frequency increases slightly over the Mach number range exciting a given mode. Now, defining a Strouhal number as $\mathrm{St}=f L_{c} / U_{\mathrm{E}}$, with $L_{c}$ defined as the cavity width measured at half the cavity depth plus the radius of the upstream flow-side cavity corner, the mean value of the points giving the maximum excitation of the individual modes take the value 0.46 .

\section{B. Influence of $10 \mathrm{~Hz}$ tone on flow generated whistling}

Adding a strong, low frequency oscillation to the system was found to considerably influence the acoustics.

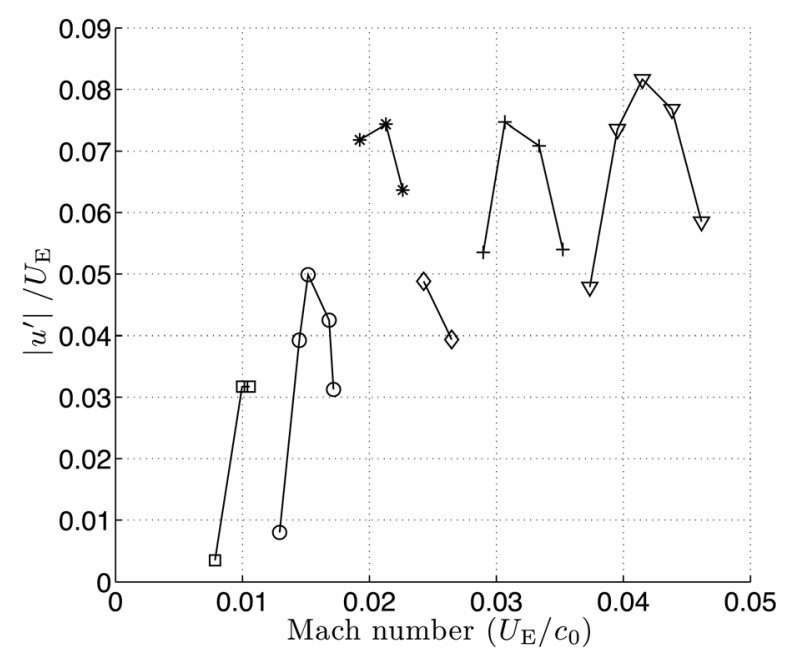

FIG. 2. Normalized particle velocity amplitudes measured at the pipe's entry section at some Mach numbers. Square: second mode $(503 \mathrm{~Hz})$, circle: third mode $(758 \mathrm{~Hz})$, star: fourth mode $(1013 \mathrm{~Hz})$, diamond: fifth mode $(1259 \mathrm{~Hz})$, plus: sixth mode $(1519 \mathrm{~Hz})$, triangle: eighth mode $(2020 \mathrm{~Hz})$. 

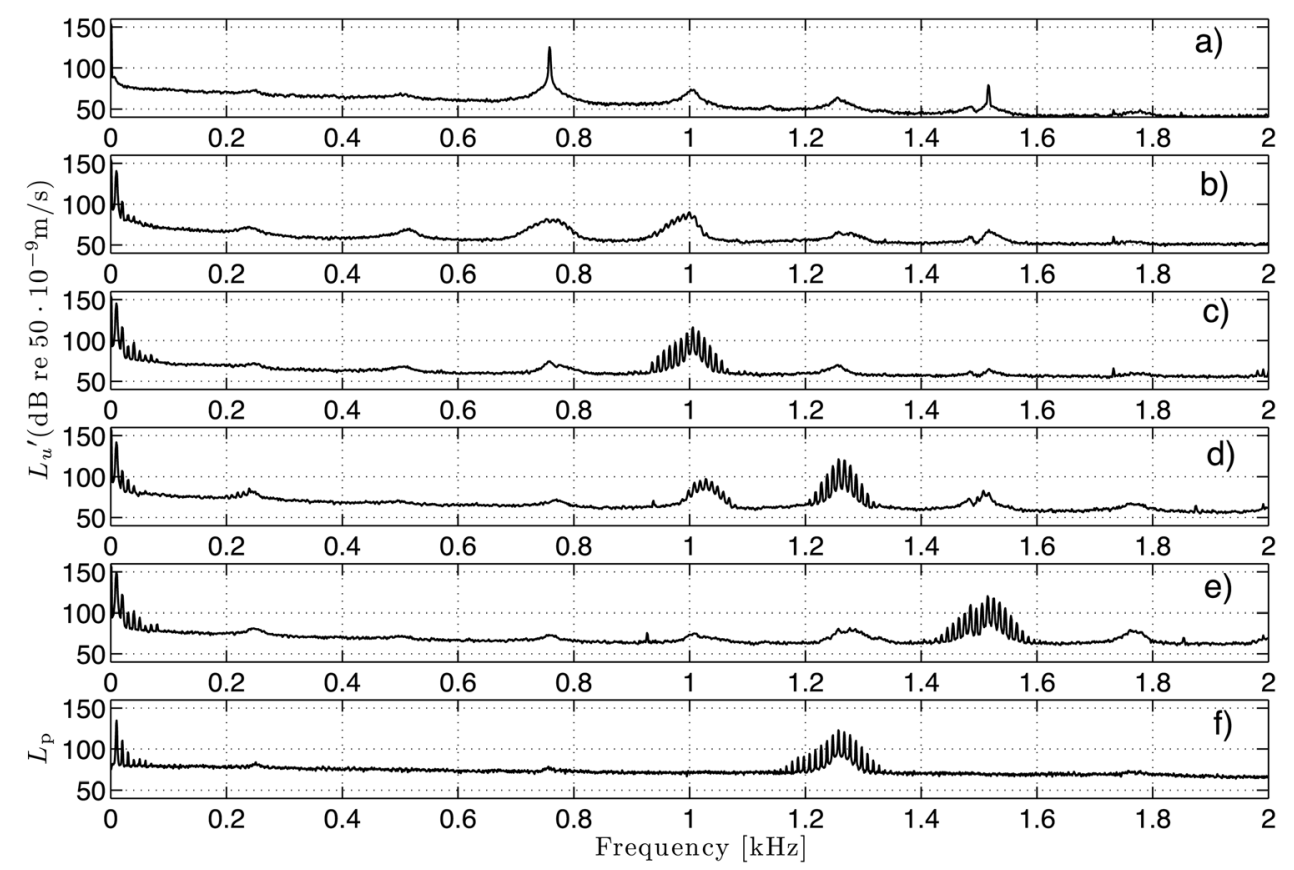

FIG. 3. Measured frequency spectra. Panels (a)-(e) show particle velocity levels for the following Mach number and $10 \mathrm{~Hz}$ oscillation conditions: (a) $M=0.15, u_{10 \mathrm{~Hz}}^{\prime} / U_{0}=0.00$; (b) $M=0.015, u_{10 \mathrm{~Hz}}^{\prime} / U_{E}=0.28$; (c) $M$ $=0.015, \quad u_{10 \mathrm{~Hz}}^{\prime} / U_{E}=0.49 ; \quad$ (d) $M=0.023, \quad u_{10 \mathrm{~Hz}}^{\prime} / U_{E}=0.22 ; \quad$ (e) $M=0.023, u_{10 \mathrm{~Hz}}^{\prime} / U_{E}=0.55$. Panel (f) shows the sound pressure level (rel. $20 \times 10^{-6} \mathrm{~Pa}$ ) measured at mid pipe position in a case where whistling around the third mode first was excited by the flow and the energy then shifted to the fifth mode by an appropriate $10 \mathrm{~Hz}$ signal.

Depending on its strength, it would lower the magnitude of the flow excited whistling or move it to a different modal order. Figure 3 illustrates this by showing frequency spectra for six different scenarios. For representational clarity, the spectra are averaged using Welch's method. Panel (a) shows whistling at the frequency of the third longitudinal mode excited at a Mach number of 0.015 . In panel (b) a $10 \mathrm{~Hz}$ oscillation is added at a level $\left|u_{10}^{\prime}\right| / U_{E}=0.28$. We see that this lowered the whistling peak with more than $40 \mathrm{~dB}$. In panel (c) the $10 \mathrm{~Hz}$ oscillation increases to $\left|u_{10}^{\prime}\right| / U_{E}=0.49$. We now see that the energy is centered around the fourth longitudinal mode, and also that we no longer have a single peak, but a cluster of peaks at $10 \mathrm{~Hz}$ intervals. Panels (d) and (e) further show spectra resulting from adding $10 \mathrm{~Hz}$ oscillations of amplitudes $\left|u_{10}^{\prime}\right| / U_{E}=0.22$ and 0.55 to an original fourth mode signal generated at Mach number 0.023. The bottom panel (f) shows the spectrum measured by a microphone probe in the middle of the pipe. In this case whistling around the 3rd mode was first generated by the pure flow, and then by adding an appropriate $10 \mathrm{~Hz}$ tone, the oscillation shifted to the region of the fifth mode. This mode has a maximum pressure in the middle of the pipe. Again we see that energy is distributed among the cluster of peaks at $10 \mathrm{~Hz}$ intervals. The situation corresponds to the relatively high levels at the frequency of the fifth mode, indicated by diamond markers in Fig. 5.

Figure 4 shows time signals corresponding to the lower four panels of Fig. 3 for one period of the $10 \mathrm{~Hz}$ signal. In all the plots we see the high frequency oscillations unevenly superposed on the signal. Note that the high frequency oscillations are located differently on the velocity and pressure signals, and that the time panels do not have a common reference time. They represent typical single cycle long time signals taken from the complete recordings for the different flow and acoustic conditions.

Figures 5 and 6 provide extra information on the addition of the $10 \mathrm{~Hz}$ oscillation where whistling at the frequen- cies of the third and fourth longitudinal modes were generated at Mach numbers 0.017 and 0.023 , respectively. We also see here that by adding and increasing the $10 \mathrm{~Hz}$ oscillation, the whistling levels are first lowered before the dominant peaks shift to the higher harmonics. Note that Fig. 3 shows that the addition of a $10 \mathrm{~Hz}$ oscillation distributed the modal energy over a cluster of peaks. The solid lines of Figs. 5 and 6 show normalized amplitudes based on an integration of the dominant peak in the cluster region using a 10 $\mathrm{Hz}$ integration bandwidth, while the dashed shows amplitudes based on the energy of the whole cluster.

\section{Whistling generated by $10 \mathrm{~Hz}$ oscillation alone}

In the case where there was no airflow through the pipe, the whistling phenomenon could be excited by a $10 \mathrm{~Hz}$ oscillation. The required velocity magnitudes $\left(\left|u_{10 \mathrm{~Hz}}^{\prime}\right|\right)$ were of
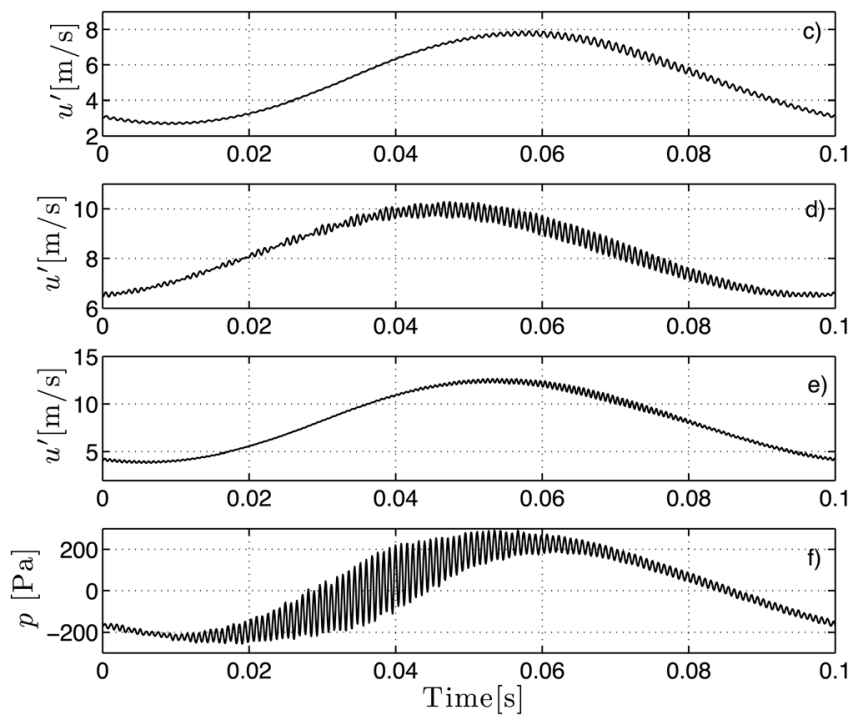

FIG. 4. Time signals corresponding to panels (c)-(f) of Fig. 3. 


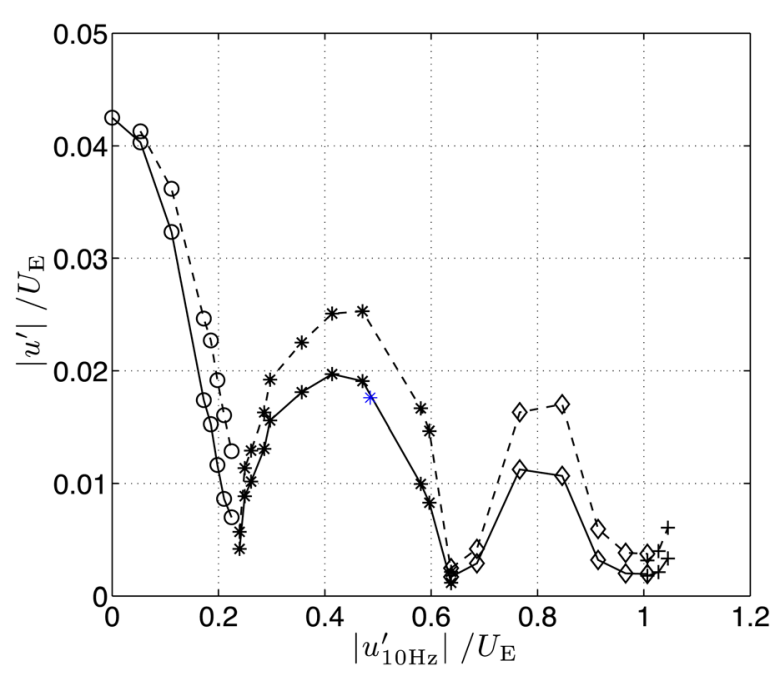

FIG. 5. (Color online) Effect of increasing $10 \mathrm{~Hz}$ tone amplitude on whistling amplitude. The first point is third harmonic excited at Mach number $M=0.017$. Solid line gives amplitude based on dominant peak and dashed line represents amplitude based on the cluster of peaks. For marker annotation see Fig. 2.

the same order as the $U_{e}$ velocity values normally exciting the whistling. Figure 7 shows an example of the measured signal. Both parts of the $10 \mathrm{~Hz}$ cycle are positive since the hot wire measures magnitude but not direction. The difference in heights is due to the difference in entry and exit flow conditions. The high peak appears more turbulent than the low peak and is suspected to correspond to the outflow phase. During outflow a free jet is formed. Figure 8 shows the normalized magnitudes of the excited whistling as function of the normalized $10 \mathrm{~Hz}$ oscillation amplitude. The higher of the two peaks of Fig. 7 was chosen for the abscissa for Fig. 8.

\section{SUMMARY AND DISCUSSION}

The experimental results show that a constant airflow above about $3 \mathrm{~m} / \mathrm{s}$ (Mach number 0.009) will excite whistling at the frequencies of the pipe's longitudinal acoustic modes in a $627 \mathrm{~mm}$

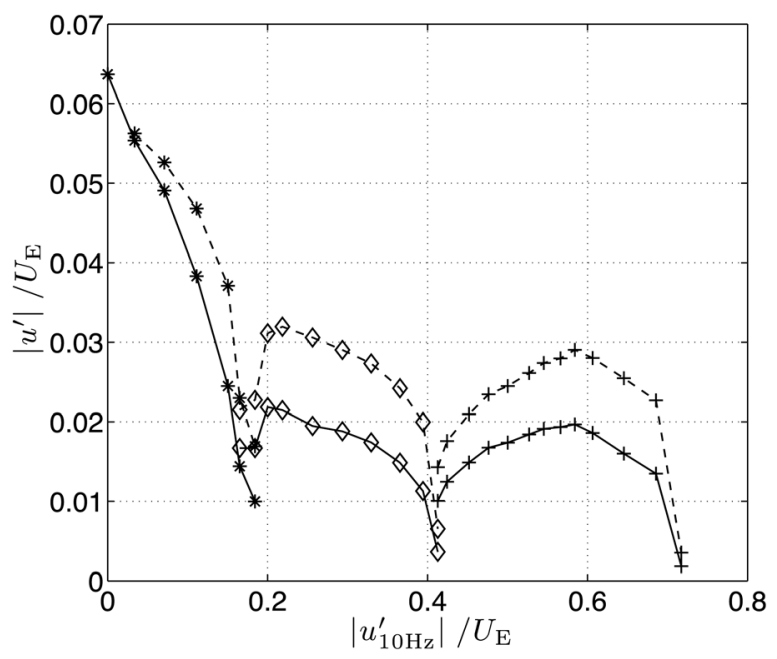

FIG. 6. Effect of increasing $10 \mathrm{~Hz}$ tone amplitude on whistling amplitude. The first point is fourth harmonic excited at Mach number $M=0.023$. Solid line represents amplitude based on dominant peak, dashed line represents amplitude based on the cluster of peaks. For marker annotation see Fig. 2.

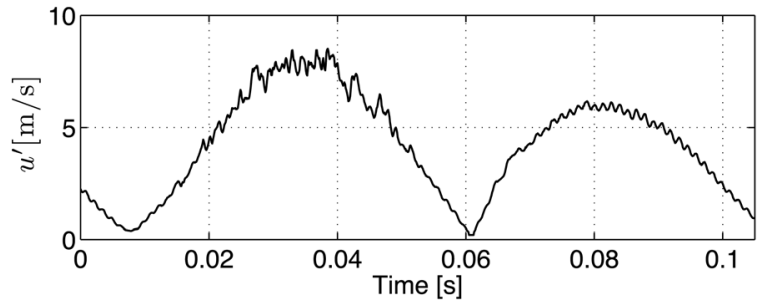

FIG. 7. Time plot showing about one cycle of the $10 \mathrm{~Hz}$ signal in the case where there is no flow in the system. The signal excited whistling at the frequency of the third pipe mode. Note that the hot-wire probe measured the absolute value of the particle velocity.

long, $25.4 \mathrm{~mm}$ inner diameter corrugated pipe, and that a superposed $10 \mathrm{~Hz}$ oscillating flow, with velocity amplitudes of the same order, will alter the acoustic field in a systematic manner.

Several mid-pipe pressure measurements were taken simultaneously with the velocity measurements to compare the signal amplitudes taking into account that odd modes have pressure anti-nodes at the mid-pipe position. For a perfect standing wave in a pipe having homogeneous Dirichlet $(p=0)$ end conditions, the mid-pipe pressure for odd modes is related to the pipe-end particle velocity by the specific acoustic impedance for plane waves, $\rho_{0} c_{O}=413.3 \mathrm{Ns} / \mathrm{m}^{3}$ at $20{ }^{\circ} \mathrm{C}$. For the third mode investigation, depicted in Fig. 5, with no $10 \mathrm{~Hz}$ oscillation imposed, the mid-pipe pressure amplitude was measured at $166.7 \mathrm{~Pa}$. The particle velocity measured as $0.25 \mathrm{~m} / \mathrm{s}$ at the entry section yields the ratio $\left|u^{\prime}\right| /\left|p_{\text {midpipe }}\right| / \rho_{0} c_{0}$ to be 0.62 . Adding a $10 \mathrm{~Hz}$ oscillation strong enough to move the whistling to the fifth mode, the amplitudes (single dominant peak values) were found to be $49.8 \mathrm{~Pa}$ and $0.12 \mathrm{~m} / \mathrm{s}$, yielding the ratio 0.51 . It was also possible to apply this to the fourth mode investigation depicted in Fig. 6. Here, the $10 \mathrm{~Hz}$ signal shifts the whistling to the fifth mode, where the corresponding pressure and velocity were measured as $123.7 \mathrm{~Pa}$ and $0.17 \mathrm{~m} / \mathrm{s}$, yielding a ratio 0.56 . The reason for this difference in directly measured velocities and the velocities derived from pressure measurements is probably due to the nature of the acoustic fields in the region of the entry section and further into the pipe. Three-dimensional effects will play a part in the

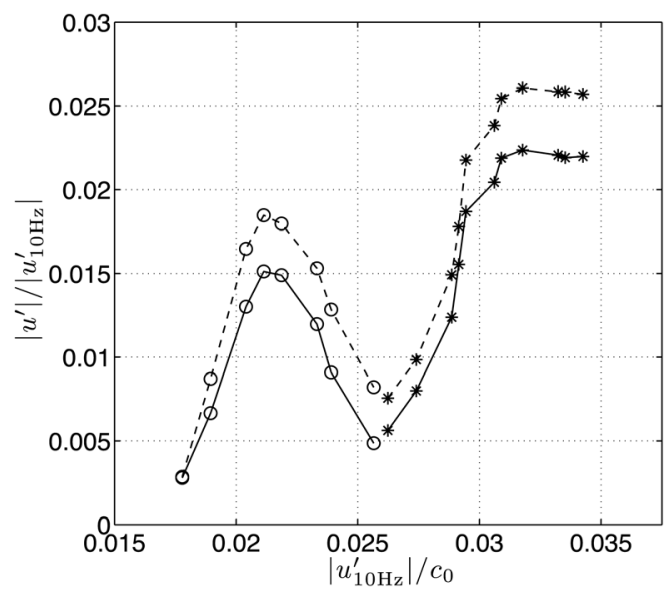

FIG. 8. Whistling generated by the $10 \mathrm{~Hz}$ signal alone (no flow in the system). Circle: third mode, star: fourth mode. Solid line represents amplitude based on dominant peak, dashed line gives amplitudes based on the cluster of peaks. 
former. The effected changes from a three-dimensional field to a one-dimensional one also applies to the flow field. The average velocity significantly within the interior of the pipe will be higher than the measured velocity at the entry surface. This is due to a contraction effect, i.e., that the flow in the pipe is confined to a central core with a smaller cross section than the one of the entry section. An idealization of our experimental setup is that of flow escaping from a large vessel through an inwardly projecting tube-a Borda tube. Gilbarg ${ }^{11}$ has shown that the contraction factor (the area ratio) for a Borda tube takes an asymptotic value of 0.5 in the case of an infinite diameter outer vessel. In the case of a jet from a sharp edged circular hole, Birkhoff and Zarantonello ${ }^{12}$ quote a contraction factor of 0.61 . It is interesting to note that the particle velocity fractions presented above correspond numerically to the region of the reported contraction factors. The extent to which the same parameter links the entry section and in-pipe velocities for both the flow and acoustic fields will be investigated further in our future work.

Figure 4 indicates that the whistling phenomena excited by a combination of flow and a $10 \mathrm{~Hz}$ oscillation becomes strong when the $10 \mathrm{~Hz}$ tone reaches a value close to its maximum. It is interesting to compare flow conditions for the modes shown in Figs. 5 and 6 with the modes excited by non-oscillating flows in Fig. 2. This raises the question of whether or not the combined velocity given by the addition of a large fraction of the $10 \mathrm{~Hz}$ amplitude to the mean flow velocity, in general, will excite the same mode as a nonoscillating flow with the same velocity.
${ }^{1}$ U. R. Kristiansen and G. A. Wiik, "Experiments on sound generation in corrugated pipes with flow," J. Acoust. Soc. Am. 121, 1337-1444 (2007).

${ }^{2}$ V. Debut, J. Antunes, and M. Moreira, "Flow-acoustic interaction in corrugated pipes: Time domain simulation of experimental phenomena," in Ninth International Conference on Flow-Induced Vibration, Prague, Czech Republic, 2008, pp. 417-425.

${ }^{3} \mathrm{H}$. Goyder, "On the modelling of noise generation in corrugated pipes," J. Pressure Vessel Technol. 132(4), 041304 (2010).

${ }^{4}$ D. Tonon, B. J. T. Landry, S. P. C. Belfroid, J. F. H. Willems, G. J. C. Hofmans, and A. Hirschberg, "Whistling of a pipe system with multiple side branches: Comparison with corrugated pipes," J. Sound Vib. 329, 1007-1024 (2010).

${ }^{5}$ G. Nakiboglu, S. P. C. Belfroid, J. Golliard, and A. Hirschberg, "On the whistling of corrugated pipes: Effect of pipe length and flow profile," J. Fluid Mech. 672, 78-108 (2011).

${ }^{6}$ S. P. C Belfroid, R. J. Swindell, and N. Kitney, "Flow induced pulsations due to flexible risers," in Offshore Technology Conference, Houston Texas, 4-7 May 2009, Report No. OTC 19904.

${ }^{7}$ L. E. Kinsler, A. R. Frey, A. B. Coppens, and J. V. Sanders, Fundamentals of Acoustics (Wiley, New York, 2000), pp. 272-301.

${ }^{8}$ U. Kristiansen, P-O. Mattei, C. Pinhede, and M. Amielh, "Measurements on tones generated in a corrugated flow pipe with special attention to the influence of a low frequency oscillation," in Proceedings of the 34th Scandinavian Symposium on Physical Acoustics, Geilo, Norway, 30 January-2 February 2011.

${ }^{9}$ N. Delprat, "Low-frequency components and modulation processes in compressible cavity flows," J. Sound Vib. 329, 4797-4808 (2010).

${ }^{10}$ D. Tonon, G. Nakiboglu, J. Golliard, and A. Hirschberg, "Voice of the dragon: The mystery of the missing fundamental mode," in Proceedings of 20th International Symposium on Music Acoustics, Sydney and Katoomba, Australia, 25-31 August, 2010, Report No. 29.

${ }^{11}$ Encyclopedia of Physics, edited by S. Flügge (Springer, Berlin, 1960), Vol. IX, Fluid Dynamics III, pp. 340-343.

${ }^{12} \mathrm{G}$. Birkhoff and E. H. Zarantonello, Jets, Wakes, and Cavities (Academic, New York, 1957), pp. 221-235. 